\title{
Gabapentin Supplemented With Ropivacain Block of Trigger Points Improves Pain Control and Quality of Life in Trigeminal Neuralgia Patients When Compared With Gabapentin Alone
}

\author{
Laurinda Lemos, MD, ${ }^{*} \dagger$ Sara Flores, $\dagger$ Pedro Oliveira, PhD, + and Armando Almeida, PhD*
}

\begin{abstract}
Objective: Pain control in trigeminal neuralgia (TN) is achieved using anticonvulsivants, mainly carbamazepine. When this drug cannot be used, other drugs like gabapentin (GBP) have been used to provide adequate pain control. To improve the therapeutic effect of GBP, we evaluated the clinical efficacy of associating GBP with ropivacain (ROP) analgesic block of facial trigger points in $\mathrm{TN}$ patients.
\end{abstract}

Design: Thirty-six TN patients were randomly assigned during 4 weeks to 1 of the following protocols: Protocol I-daily oral GBP administered in a titrated dose; Protocol II-ROP applied as analgesic block to TN trigger points once a week; Protocol III-daily oral GBP plus ROP once a week. Protocol II had to be discontinued in 7/12 patients owing to insufficient pain control. Pain intensity was evaluated by the Visual Analog Scale (VAS) and disability was assessed by Sickness Impact Profile.

Results: When compared with Protocol I, Protocol III $(\mathrm{GBP}+\mathrm{ROP})$ patients showed (1) a reduction of VAS score after 7 and 28 days of treatment, an effect that was still present 6 and 12 months later; (2) a faster reduction of VAS score using a significantly lower dose of GBP; (3) a smaller total and daily GBP dose at the end of the treatment, which resulted in a total absence of adverse side effects; and (4) an improvement of the functional well-being measured by the Sickness Impact Profile. The number needed to treat (NNT) $(\mathrm{GBP}+\mathrm{ROP}$ vs. GBP protocols) to obtain $1 \mathrm{GBP}+\mathrm{ROP}$-treated patient with at least $50 \%$ pain relief was 1.71 (day 7) and 2.40 (day 28).

Conclusions: The association of GBP and ROP is safe, without side effects and results in an important clinical benefit associated to an improvement of the functional health status of $\mathrm{TN}$

Received for publication April 16, 2007; accepted August 8, 2007.

From the *Health and Life Sciences Research Institute (ICVS), School of Health Sciences; ¥Production and Systems Engineering, University of Minho, Braga; and †Hospital Center of Alto Ave, Unit of Fafe, Fafe, Portugal.

Supported by Fundação para a Ciência e Tecnologia (FCT) Project no POCTI/NSE/46399/2002, FEDER and Fundação Calouste Gulbenkian Project no. 74551.

Reprints: Prof Armando Almeida, PhD, Health and Life Sciences Research Institute, School of Health Sciences, University of Minho, Campus de Gualtar, 4710-057 Braga, Portugal (e-mail: aalmeida@ ecsaude.uminho.pt).

Copyright (C) 2007 by Lippincott Williams \& Wilkins patients when compared with GBP alone. This may constitute a therapeutic alternative for pain control in TN patients who cannot be treated with carbamazepine.

Key Words: trigeminal neuralgia, gabapentin, ropivacain, analgesic block, pain intensity, Quality of Life, SIP

(Clin J Pain 2007;00:000-000)

$\mathrm{T}$ rigeminal neuralgia $(\mathrm{TN})$ has a strong clinical impact because its severe and unpredictable pain periods induce important functional and psychoaffective changes in patients. ${ }^{1}$ Pain is described as burning or shooting and, is characterized by paroxysmal "electric shocklike" intense episodes, with an instantaneous progression from the onset to the peak. Pain lasts from several seconds to less than 2 minutes and is triggered by a non-noxious stimulus, usually when eating, speaking, or touching on the naso-labial fold or perioral region (trigger points). ${ }^{2}$ Treatment options can include a variety of drug therapies, but progressively more invasive techniques may be needed. ${ }^{3}$

TN does not respond to primary analgesics and the solution is the use of adjuvant analgesics, mainly anticonvulsivants (ACs). Several ACs are known to stabilize plasma membrane of peripheral nerve fibers by inhibiting ectopic discharges in altered membranes. ${ }^{4}$ Carbamazepine (CBZ) has been the most efficacious (beneficial in $70 \%$ of patients) and most used $\mathrm{AC}$ in the treatment of $\mathrm{TN}^{1}$ and was the only drug evaluated in large placebo-controlled trials. ${ }^{1,5}$ However, the main problem concerning the use of ACs is the tolerance to the drug doses controlling pain, owing to side effects (dizziness, somnolence, and ataxias). ${ }^{4,6}$ The absence of CBZ efficacy in some patients, cases of intolerance, ${ }^{7}$ hypersensitivity, fluid retention, ${ }^{8}$ drug interactions, a narrower therapeutic index and a higher degree of adverse side effects than recent drugs like gabapentin (GBP) has led to a progressively increased use of the latter drug in several neuropathic pain syndromes. ${ }^{9-12}$ GBP has been used alone ${ }^{13}$ or in association with CBZ or iamotrigine ${ }^{14}$ and results in pain reduction in at least $47 \%$ of TN patients. However, it should be noted that the effectiveness of GBP and other drugs like 
phenytoin and topiramate in TN have not been evaluated in large scale trials, ${ }^{1}$ probably because of the relatively rarity of this pathology.

Surprisingly, although the association of analgesics with different mechanisms of action may putatively result in analgesia potentiation and less adverse side effects, the possibility for associating drug therapies has been explored very little until present. ${ }^{4}$ To the best of our knowledge, and excluding the association of different ACs, ${ }^{14}$ no treatment associating different drug classes have been described and no multimodal prospective trials have been performed for TN. A potential adjunctive treatment that have not been explored, is the combination of an $\mathrm{AC}$ with an analgesic block of $\mathrm{TN}$ facial trigger points using a local anesthetic. These drugs have a complementary mechanism of action because local anesthetics at low doses block anomalous membrane excitability and ACs block also ectopic activity of peripheral fibers without abolishing sensory transmission. ${ }^{15}$ Thus, their association may have improved control over the instability of membrane potential and thus reinforce the clinical improvement of $\mathrm{TN}$ patients.

The objective of the present study was to improve the clinical effect of GBP as an alternative protocol to CBZ, whenever this drug cannot be the first choice treatment. We evaluated the therapeutic efficacy of associating the oral administration of GBP with ropivacain (ROP) local analgesia of $\mathrm{TN}$ trigger points, in comparison with GBP monotherapy. ${ }^{13} \mathrm{We}$ selected the local anesthetic ROP which has a lower risk of cardiovascular and nervous toxicity and a higher affinity for $A \delta$-nociceptive and $C$-nociceptive fibers than $A \beta$ innocuous fibers when compared with bupivacain. ${ }^{16}$ Additionally, ROP has a smaller risk in case of continuous or successive bolus administration than levobupivacain. The outcomes analyzed were (1) the degree of pain reduction, (2) the number of daily paroxysmal pain crises, (3) the time necessary to obtain satisfactory clinical results, (4) the degree of adverse side effects, and (5) the impact upon Quality of Life. Part of this study has been presented in abstract form. ${ }^{17}$

\section{METHODS}

The organization of the present study followed as possible the recommendations for improving the quality of reports of parallel-group randomized trials. ${ }^{18}$

\section{Patients-Entry and Exclusion Criteria}

Participants for this study were recruited from the Chronic Pain Unit of the Hospital Center of Alto Ave, Portugal during the years 2003 to 2006. Patients were eligible for the study if they had a pain intensity Visual Analog Scale (VAS) score (see below) $\geq 6$ and met the consensus criteria for the diagnosis of primary (idiopathic) TN. ${ }^{8}$ The inclusion criteria were:

- Occurrence of episodes of intense facial paroxysmal pain in territory innervated by the trigeminal nerve (VAS score $\geq 6$ )

- Presence of a normal neurologic examination
- Normal neuroimaging analysis

The following exclusion criteria were also considered:

- Patient refuse to participate

- Psychologic instability

- Atypical pain location (eg, no specific trigger points)

- Anticlotting therapy

- Secondary TN ${ }^{2}$

- Multiple sclerosis

- Temporomandibular joint disorders

- Neoplasias

- Altered neurologic profile

- Hypoesthesia

- Dysesthesia

- Anesthesia

- Paresis

- Association with other cranial nerve neuralgias (eg, glossopharyngeal neuralgia)

- Imagiologic alterations

- Proposed surgical intervention

- Compression of the Gasser ganglion

- Preference of the patient

The treatment protocols used were accepted by the Hospital Ethical Committee and the patients were informed that (1) they would be submitted to 1 of 3 different protocols to solve their pain problem and (2) they could drop or change treatment if no pain control was achieved. All patients signed an informed consent.

\section{Random Allocation}

It has been recommended that a detailed description of the expanded criteria followed for adequate allocation of patients to treatment groups should prevail over minimal description. ${ }^{19}$ The $36 \mathrm{TN}$ patients defined to enter the study were the first 36 arriving to the chronic Pain Unit and fulfilling the inclusion criteria (Table 1; Fig. 1). The first patient was presented at the entrance of the study with a box containing 36 sealed code opaque envelops, where the treatment protocol to be followed was specified (12 envelops for each protocol, which was written in a cardboard inside) [method adapted from the unrestricted (simple) randomization described by Doig and Simpson $\left.{ }^{20}\right]$. The random attribution of an envelope to the patient ended when he/she takes 1 from the box without looking inside. The second patient fulfilling the entry criteria to the study was presented to the box with the 35 envelopes left, which were mixed before the second patient took an envelope. The same sequence was followed to preserve the random allocation of the 34 other patients to the 34 envelopes left.

\section{Treatment Protocols}

Patients were allocated to one of the following treatment protocols (Fig. 1):

\section{Protocol I}

Protocol I - treatment using only GBP, ${ }^{13}$ which was administered orally in progressively higher doses. ${ }^{16}$ The first 2 days, patients were given $100 \mathrm{mg} / \mathrm{d}$ oral GBP at 
TABLE 1. Baseline Characteristics of the Patients

\begin{tabular}{|c|c|c|c|c|}
\hline & $\begin{array}{c}\text { Protocol I } \\
(\text { GBP })(n=12)\end{array}$ & $\begin{array}{c}\text { Protocol II } \\
(\text { ROP) } \\
\left(\mathbf{n}=12^{*}\right) \\
\end{array}$ & $\begin{array}{c}\text { Protocol III } \\
(\text { GBP + ROP) } \\
(\mathbf{n}=12)\end{array}$ & $P * *$ \\
\hline $\begin{array}{l}\text { Age (y, average } \\
\text { and SD) }\end{array}$ & $61(10.8)$ & $62(7.7)$ & $64(19.2)$ & 0.35 \\
\hline $\begin{array}{l}\text { Sex (women/ } \\
\text { total) }\end{array}$ & $5 / 12$ & $6 / 12$ & $9 / 12$ & 0.23 \\
\hline \multicolumn{5}{|c|}{ Pain location (trigeminal branches) } \\
\hline $\begin{array}{l}\text { V1 or V2 or } \\
\text { V3 }\end{array}$ & 2 & 4 & 3 & \\
\hline $\begin{array}{l}\mathrm{V} 1+\mathrm{V} 2 \text { or } \\
\mathrm{V} 2+\mathrm{V} 3\end{array}$ & 7 & 6 & 8 & \\
\hline $\mathrm{V} 1+\mathrm{V} 2+\mathrm{V} 3$ & 3 & 2 & 1 & \\
\hline $\begin{array}{l}\text { Facial side } \\
\text { (right/total) }\end{array}$ & $8 / 12$ & $7 / 12$ & $9 / 12$ & \\
\hline $\begin{array}{l}\text { Type of pain } \\
\text { (electric } \\
\text { shock) }\end{array}$ & 12 & 12 & 12 & \\
\hline \multicolumn{5}{|c|}{ Pain duration at day 0} \\
\hline $1-2 y$ & 7 & 8 & 4 & \\
\hline $3-4 y$ & 4 & 4 & 3 & \\
\hline 5 and more & 1 & 0 & 5 & \\
\hline
\end{tabular}

*The 12 patients were included in the study on day 0 of the treatment, at days 7 and 30 , only 5 patients showed adequate pain control.

$* * P$ values were obtained by Kruskal-Wallis test.

night by prescription from the hospital staff; from the third to the seventh day, they progressively received from 100 to $300 \mathrm{mg} / \mathrm{d}$ oral GBP to decrease pain intensity (until VAS $<6$; see below VAS definition). From the seventh day to the end of the study (28th day), the dose taken by each patient could amount to 300 to $900 \mathrm{mg} / \mathrm{d}$ oral GBP if the pain intensity reached a VAS score $\geq 6$ (see below). Each 7 days, during their visit to the Pain Unit, patients were evaluated, the VAS score was recorded, and GBP titration was verified. Patients were told that each increase in GBP daily dose should be restricted to $100 \mathrm{mg} / \mathrm{d}$ and taken when they felt worse. It is the experience of our Pain Unit that all TN patients with VAS scores of 9 to 10 felt much better and relieved when their VAS score dropped below 6. Because patients express their pain experience in this scale, the motivational-affective impact of being free from their excruciating pain made them feel well and helped them cope with some pain with all spectrum values of VAS scale below 6 . Thus, we defined the VAS value of 6 as the threshold for increasing drug therapy. In practice, however, patients were free to increase their GBP dose by $100 \mathrm{mg} / \mathrm{d}$ whenever they felt the necessity for improving their pain control.

\section{Protocol II}

Protocol II-administration of a superficial analgesic block with ROP to the trigger point(s) inducing paroxysmal pain crises in TN patients. The injection was performed at the Pain Unit under sterile conditions, using a 27-gauge needle for administering subcutaneously $2 \mathrm{~mL}^{21}$ of a $2 \mathrm{mg} / \mathrm{mL}$ ROP solution in each trigger point
(Fig. 2). Each local block was performed once a week ${ }^{22}$ during the 1-month treatment (days 0, 7, 14, 21, and 28). Patient usually reported immediate pain relief.

\section{Protocol III}

Protocol III-treatment using GBP plus ROP $(\mathrm{GBP}+\mathrm{ROP})$. The GBP and ROP were administered following the same rationale as for Protocols I and II, respectively. Thus, at day 0 , a ROP analgesic block was performed on trigger points and $100 \mathrm{mg}$ of GBP administered at night to each patient. On subsequent days, the increase in GBP daily administration followed the rationale described above for Protocol I and, each 7 days (days 7, 14, 21, and 28), a ROP block was performed as for Protocol II.

During the 28-day treatment, all patients were evaluated by the hospital staff at the first 2 days and periodically at days $7,14,21$, and 28 . During the periods between days 3 and 6,8 and 13,15 and 20, and 22 and 27, patients were at home and were requested to record their VAS pain intensity score in an individual Pain Diary provided by the hospital staff, the GBP dose (patients from Protocols I and III), and the hour when medication was taken.

Paracetamol $1000 \mathrm{mg}$ was used in this study for breakthrough pain in those cases where patients needed pain control between GBP doses, or if the study medication was not having an analgesic effect. They were instructed to take it as needed every 8 hours with a maximum of $4000 \mathrm{mg} / \mathrm{d}$. Patients were requested to keep a calendar of time and amount of rescue medication used.

After the 1-month period of protocol treatment, patients were requested to continue their treatment at home, using the same GBP dose used at day 28 (Protocols I and III). If Protocol II patients experienced a new pain episode they were instructed to return to the Pain Unit for evaluation and were provided the most adequate conventional treatment.

\section{Experimental Sequence and Primary Outcome Measures}

The application of each protocol treatment (Fig. 1) was performed by a first researcher (Experimenter 1; Dr Laurinda Lemos), who was blinded to the VAS scores of pain intensity and Sickness Impact Profile (SIP) scores of Quality of Life obtained by each patient. VAS and SIP before and along the 28 days of protocol treatment were evaluated by a second researcher (Experimenter 2; Dr Sara Flores), who was blinded to the protocol assigned to each patient. The statistical evaluation of the data was performed by a third researcher (Experimenter 3; Dr Pedro Oliveira). The mechanical procedures of mixing the envelopes for their random allocation were performed by a fourth person not belonging to the research staff of this study.

The predefined primary outcome measures were:

(1) Evaluation of pain intensity using the VAS. ${ }^{23,24}$ Patients located their relative pain in a line marked in each extremity with 0 (0: no pain —on the left) and 
FIGURE 1. Consort flowchart of the steps followed by TN patients along the experimental design of the study. Note that from the $42 \mathrm{TN}$ patients who were assessed to participate in this study, 12 were excluded before allocation owing to exclusion criteria and 7 following Protocol II had to leave the study at day 7 owing to insufficient pain control.

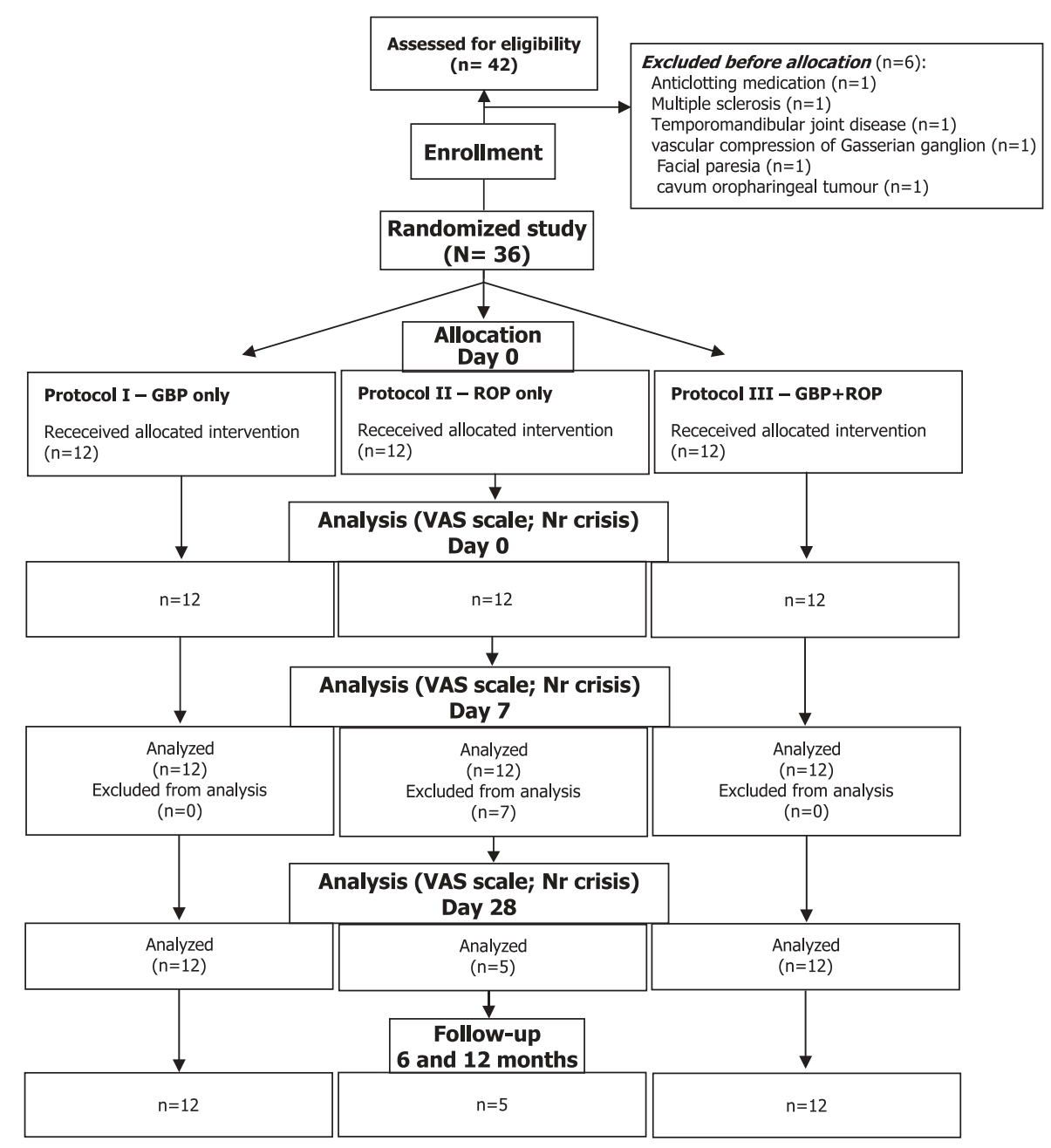

10 (10: the worst pain imaginable - on the right). Moderate pain was considered to be over $30 \mathrm{~mm}$ $(\mathrm{VAS}>3)$ and severe pain over $60 \mathrm{~mm}(\mathrm{VAS} \geq 6){ }^{25}$ A pain reduction of 2 points in the VAS scale on the $100-\mathrm{mm}$ VAS from the baseline pain score was considered to be clinically significant. ${ }^{26-28}$ Only VAS scores evaluated at the beginning of the treatment (day 0), the seventh day (day 7; just before ROP administration), and at the end of the treatment (day 28; $2 \mathrm{~d}$ after the last ROP administration) were used for statistical comparison between protocols. However, to increase GBP daily dose by $100 \mathrm{mg}$, the VAS score of the most intense pain period was determined everyday by the patient at night and recorded in the Pain Diary provided to each patient by the hospital staff.

(2) Daily number of paroxysmal pain episodes. This variable was evaluated everyday, but only values obtained at the end of the treatment period (day 28) and 5 and 11 months after the end of the treatment (follow-up) were used for statistical analysis. The follow-up evaluation was performed at the end of the day during a phone interview to each patient, who was asked (1) how many pain attacks suffered during that day or, in case of no pain, (2) how many pain attacks suffered in the worst day of the last week before interview. If no pain was felt during the last week before interview, the staff recorded 0 for the patient.

(3) NNT. Instead of comparing a drug treatment with a placebo group like the usual application of NNT formula to clinical studies, ${ }^{29,30}$ we compare the therapeutic result between a new proposed therapy (GBP + ROP protocol) and a conventional treatment (GBP protocol), as suggested by Altman. ${ }^{31}$ This allows a comparison of efficacy between the 2 clinical treatments. ${ }^{31}$ Thus, in the present study, NNT is defined as $1 /$ [the proportion of patients successfully treated with GBP + ROP (with at least $50 \%$ pain relief) - the proportion of patients successfully treated with the standard GBP monotherapy], as expressed in the equation below. The NNT of Protocol III over protocol I was determined for days 7 and 28. The 95\% confidence 
interval (CI) for each NNT value was obtained using the free calculator at the site of the University of Manchester www.phsim.man.ac.uk/nnt:

$\mathrm{NNT}=$

$\frac{1}{50 \% \text { VAS reduction GBP+ROP patients }} 50 \%$ VAS reduction GBP-only patients

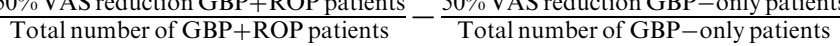

\section{Evaluation of Patient Quality of Life-SIP}

A secondary outcome measure of this study was the evaluation of the Quality of Life of patients using the SIP ("Sickness Impact Profile") $32-34$ adapted to the Portuguese population (McIntyre and Araújo-Soares, 1999 and personal communication). SIP evaluates the descriptive profile of the patients in terms of impact of the pathology analyzed upon specific day life behaviors. It is constituted by 136 questions divided along 11 categories. To analyze each patient in dimensions other than pain intensity, patients were requested by the staff to answer the SIP at the beginning (day 0) and end (day 28) of $\mathrm{GBP}+\mathrm{ROP}$ and ROP protocols. We analyzed the answers obtained at day 0 and day 28 in the following categories: "Domestic Work," "Mobility," "Communication," "Locomotion," "Eating," "Recreation-Pastimes," "Mobility," "Emotion," "Social Interaction," "Alertness," and "Rest." Additionally, the longitudinal evolution of the SIP total score was also evaluated between the beginning and end of each therapy. It should be noted that the score obtained in each category of the SIP is inversely proportional to the performing capacity of the patient.

\section{Power of the Study}

We previously determined that the number of patients allocated to each protocol should be 12, as a balance between the small incidence of TN patients in the population and a sufficient number of patients to avoid too small a sample. A total of 36 patients entered this 3 treatment parallel-designed randomized and blinded study, GBP (Protocol I), ROP (Protocol II), and GBP + ROP (Protocol III). In the context of 1-way analysis of variance (ANOVA) (single factor experiments allowing the comparison of more than 2 treatments), Montgomery ${ }^{35}$ suggests an approach for determining the sample size according to the interest of the experimenter, bearing in mind that small effects requires replication. When the null hypothesis is rejected, the mean square of treatment/mean square error statistic is a noncentral F random variable (section 4.2 of Montgomery ${ }^{35}$ ). The probability of type II error can be expressed as a function of the difference of any 2 treatments (Appendix Chart V of Montgomery ${ }^{28}$ ). In the present case, we have considered that a difference of 2 VAS units was the minimum clinically relevant decrease in pain control measured by the VAS score when comparing 2 treatments, as sustained by others. ${ }^{26-28}$ For different estimates of the standard deviation (SD) and for different number of patients, power was determined. For estimates of the SD ranging from 0.5 to 2 and number of patients ranging from 4 to 15 , the power ranged from 0.9 to 0.97 . The maximum power was observed for a SD of 1.75 and a number of patients of 12 . In addition, we also determined the real observed power at days 7 and 28 with the patients who remained in the study, using SPSS 14.0 software for Windows.

\section{Statistics}

Data are presented as media $\pm \mathrm{SD}$ along the several variables under study. Tacking into account that at days 0,7 , and 28 , data were obtained from patients of the 3 protocols tested, mean values were compared by 1-way ANOVA followed by the Tukey post hoc test. Where the homogeneity of variances was not observed, the nonparametric test of Kruskal-Wallis was used. The $\chi^{2}$ test was applied to compare the sex distribution among the 3 groups. On the other hand, because only 2 protocols were evaluated with the SIP at day 28 and at follow-ups after the end of treatments (5 and $11 \mathrm{mo}$ ), the mean values from both Protocols I and III were compared by the nonparametric Mann-Whitney test. The normal distribution of the results was verified using the KolmogorovSmirnov test, whereas the equality of variances was evaluated by the Levene test. The differences between means from the different protocols were considered significant when $P<0.05$. All calculations were carried out using SPSS 14.0 for Windows.

\section{RESULTS}

\section{Patient Baseline Characteristics}

From the $42 \mathrm{TN}$ patients assessed for eligibility, 36 patients were randomized (Fig. 1). Twelve assigned to each treatment protocol. From those 12 patients assigned to Protocol II (ROP), 7 had to abandon this therapy and were excluded from the study because local analgesia of trigger points with ROP each 7 days was insufficient to decrease pain below a VAS score of 6 for a long period. These patients were excluded from the study and moved to a conventional TN treatment after the ROP administration at day 7. Figure 1 summarizes the flow of patient in this study. The analysis of the patients in the three protocols showed no significant differences $(P=0.35$ and 0.23 , respectively) (Table 1 ) in demographic characteristics including sex and age. In each protocol, no differences were detected between patients with different $\mathrm{TN}$ trigger points owing to the rare incidence of this pathology in the population and the number of patients available for the study.

\section{Effect of Different Protocols in Pain Control}

No differences were found between patients from Protocols I (GBP; $\left.\mathrm{VAS}_{0}=8.5 \pm 1.3\right)$, II $\left(\mathrm{ROP} ; \mathrm{VAS}_{0}=\right.$ $9.2 \pm 0.9)$, and III (GBP+ROP; $\left.\mathrm{VAS}_{0}=8.8 \pm 1.6\right)$ $(P=0.45)($ Fig. 3) in pain intensity at the beginning of the treatment (day 0). This result reinforces the homogeneity of the participants and the similarity between patients allocated to the 3 protocols. After 7 days of each 
therapy (day 7), the 3 protocols reduced pain intensity (ANOVA, $P=0.03$ ) but this reduction was significantly more pronounced in patients treated with $\mathrm{GBP}+\mathrm{ROP}$ $\left(\mathrm{VAS}_{7}=4.5 \pm 1.6\right)$ compared with patients treated only with $\mathrm{GBP} \quad\left(\mathrm{VAS}_{7}=6.8 \pm 1.2 ; \quad P=0.003\right)$ or $\mathrm{ROP}$ $\left(\mathrm{VAS}_{7}=6.3 \pm 1.8 ; P=0.025\right.$ ) (Fig. 3). No differences were observed between GBP and ROP groups $(P=0.71)$. However, it should be noted that these ROP values concerned only 5 of the 12 patients who have begun Protocol II therapy. The other 7 patients had to drop the study because VAS values reached $9.0 \pm 0.8$ after 5 to 6 days with complete pain control and before rescue medication that begun around day 6 . When they arrived the Pain unit at the seventh day under rescue medication (paracetamol), they were given the expected ROP injection and moved immediately to conventional AC drug therapy (carbamazepine or GBP). At the end of the experimental period of treatment (day 28), both Protocols I and III were effective in controlling pain in all 12 patients who have begun the treatment. Although both protocols reduced pain intensity, this effect was more pronounced in patients treated with $\mathrm{GBP}+\mathrm{ROP}\left(\mathrm{VAS}_{28}=2.8 \pm 0.9\right)$ than in those treated with GBP $\left(\mathrm{VAS}_{28}=4.9 \pm 1.6 ; P<0.001\right)$. Interestingly, no differences were observed between pain intensities of GBP + ROP and the 5 ROP patients reaching the end of the study $\left(\mathrm{VAS}_{28}=3.4 \pm 0.6 ; P=0.56\right)$ (Fig. 3).

It is important to note that, in terms of time to achieve a good improvement in pain, the drop in pain
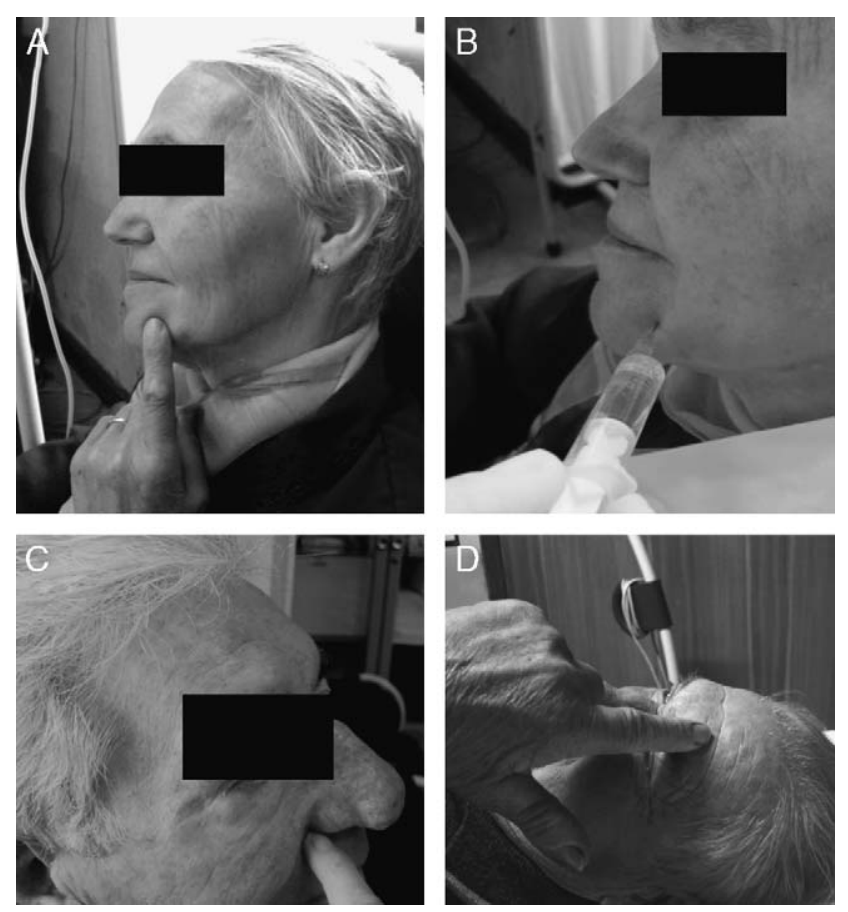

FIGURE 2. Location of trigger points in $2 \mathrm{TN}$ patients. Note their location near the V3 (A), V2 (C), and V1 (D) branches of the trigeminal nerve. $B$, The administration of ROP was performed in the area pointed as a trigger point by the patient in $(A)$.

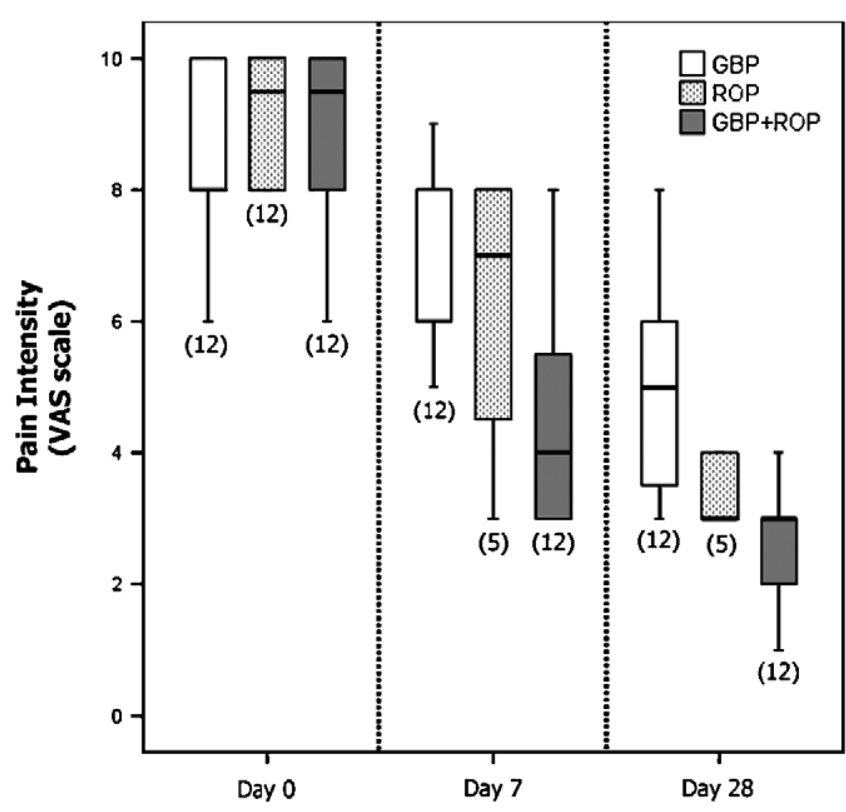

FIGURE 3. Effect of the 3 protocols (GBP, ROP, and GBP+ROP) on the Pain Intensity of TN patients along the treatment. Note the more intense and rapid reduction in pain scores following $\mathrm{GBP}+\mathrm{ROP}$ treatment. Additionally, a significant inferior pain intensity was recorded by these patients at the end of the 28day period when compared with those treated only with GBP. Note that patients evaluated in ROP group were 12 at day 0 , but only 5 at days 7 and 28. The number of patients included in the mean $(n)$ is present between brackets below the data bars. For statistical significances, see Results section.

intensity between days 0 and 7 was significantly more evident $(P<0.001)$ in patients treated with GBP + ROP $\left(\mathrm{VAS}_{\text {dif }} 7-0=4.3 \pm 1.6\right)$ than in patients treated only with GBP $\left(\mathrm{VAS}_{\mathrm{dif}} 7-0=1.8 \pm 1.0 ; P<0.01\right)$, with the decrease being near significance when compared with the 5 ROP patients continuing the study $\left(\mathrm{VAS}_{\mathrm{dif}} 7-0=\right.$ $2.9 \pm 1.4 ; P=0.057)$. Additionally, if we consider the decrease in pain intensity between days 0 and 28 , significant differences were again observed between the different protocols (ANOVA, $P=0.005$ ). The decrease in the GBP + ROP group reached $6.0 \pm 1.7$ points in the VAS scale $\left(\mathrm{VAS}_{\mathrm{dif} 28-0}\right)$, which was significantly more expressive than the $3.6 \pm 1.8$ points $\left(\mathrm{VAS}_{\mathrm{dif}} 28-0\right)$ decrease observed for GBP-treated patients $(P=0.005)$ (Fig. 3). Concerning the ROP-treated group, a significant decrease in pain intensity between days 0 and 28 $\left(\mathrm{VAS}_{28}=3.4 \pm 0.6\right)$ was shown in the same 5 patients at the end of the treatment, which reached $5.4 \pm 1.1$ $\left(\mathrm{VAS}_{\mathrm{dif}} 28-0\right)$ points (Fig. 3). No differences occurred in total pain decrease between days 0 and 28 when compared with GBP + ROP protocol $(P=0.78)$.

The baseline number of daily crises of paroxysmal sudden and intense pain was similar between patients of the 3 protocols (ANOVA, $P=0.36$ ) $\left[n_{\text {episodes }}=10.5 \pm 2.0\right.$ (GBP), $9.2 \pm 1.5$ (ROP), and $9.8 \pm 1.5$ (GBP+ROP)]. A clear decrease was observed after 28 days of treatment (ANOVA, $P<0.001$ ), with patients treated with 
GBP + ROP $\left(n_{\text {episodes }}=2 \pm 1.0\right)$ showing a significantly lower number of pain crises than those treated only with GBP $\left(n_{\text {episodes }}=4.8 \pm 1.4 ; P<0.001\right)$ or ROP $\left(n_{\text {crises }}=6.8 \pm 0.8 ; P<0.001\right)$ (Fig. 4). It should be recalled that at day 28, the number of patients in Protocol II (ROP) was 5, but in this case the improvement was far from being comparable with the GBP + ROP treatment.

\section{Follow-up}

Five months after the end of the 28 days of treatment, the number of daily pain episodes was significantly lower $(P<0.001)$ in the GBP + ROP group $\left(n_{\text {episodes }}=1.6 \pm 1.4\right)$ than in ROP group $\left(n_{\text {episodes }}=4.2 \pm 0.8 ; P=0.001\right)$, whereas in the GBPtreated group the number of daily episodes has even raised again $\left(n_{\text {episodes }}=6.3 \pm 1.1 ; P<0.001\right)$ (Fig. 4). Eleven months after the end of the treatment, the GBP + ROP group of patients presented a statistically significant lower number of daily pain episodes $(1 \pm 0.7)$ when compared with both GBP $(2.3 \pm 0.5 ; \quad P<0.001)$ and ROP $(2.6 \pm 0.6 ; P<0.001)$ (Fig. 4). Note that only 5 patients were evaluated in Protocol II (ROP) at these 2 time points of follow-up. Again, the improvement in ROP patients was inferior to that obtained by GBP + ROP patients.

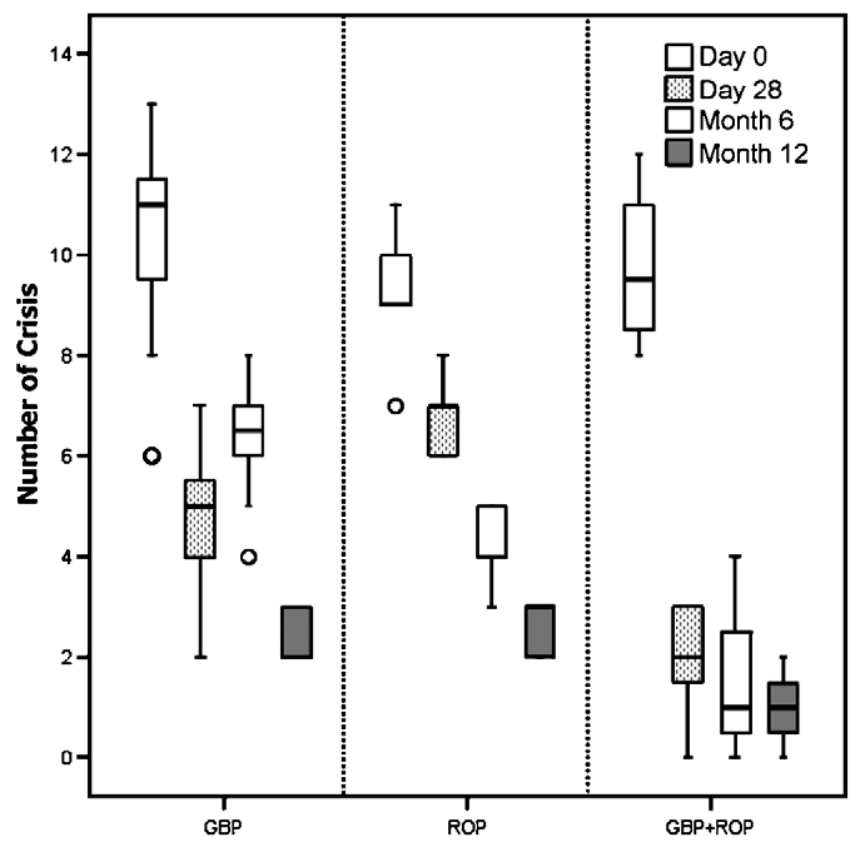

FIGURE 4. The number of daily episodes of paroxysmal pain at the end of the treatment protocols and 5 and 11 months later. It is evident a much more rapid and significant decrease in pain episodes induced by the application of the associative therapy GBP+ROP performed in Protocol III, especially in comparison with GBP monotherapy. It should be noted that following Protocol I (GBP only), the number of daily pain episodes even enhanced from the end of the treatment to 5 months later. Additionally, patients evaluated in ROP group were 12 at day 0 , but only 5 at day 28 and after the follow-ups 5 and 11 months later. For statistical significances see Results section.

\section{GBP Daily Dose}

At days 1 and 2, all GBP and GBP + ROP patients took $100 \mathrm{mg} / \mathrm{d}$ GBP. At day 7, GBP and GBP + ROP patients were taken 200 or $300 \mathrm{mg} / \mathrm{d}($ mean $=266.67 \mathrm{mg} / \mathrm{d})$. Protocol III (GBP + ROP) resulted in a lower final daily dose of GBP $(300 \mathrm{mg} / \mathrm{d}$ in all patients) at the end of the treatment (day 28) than in patients following Protocol I $($ mean $=525 \mathrm{mg} / \mathrm{d} ;$ minimum $=300 \mathrm{mg} / \mathrm{d}$, maximum $=$ $600 \mathrm{mg} / \mathrm{d}$ ) (Fig. 5). No GBP was administered to ROPtreated patients.

\section{NNT}

When comparing the clinical benefit obtained by GBP + ROP and ROP protocols, the NNT for the treatment associating GBP + ROP (Protocol III) over the GBP treatment (Protocol I) was 1.71 (95\% CI: 1.23 $3.67)$ at day 7 and 2.40 (95\% CI: 1.46-8.49) at the end of the therapy (day 28).

\section{Power of the Study}

The observed power of the present study was, for 0.90 for day 7 and 0.98 for day 28 , when the alternative hypothesis is set based on the observed values. For the power of the study calculated before the experimental period, see the Methods section.

\section{Patient Quality of Life-SIP}

For all categories studied, we analyzed only the evolution of the Quality of Life scores obtained between the beginning and the end of the treatment period (Table 2). Accordingly, between the beginning (day 0) and the end (day 28) of the treatment, it was observed that (Table 2) (1) Protocol III patients showed a significant improvement in all SIP categories $(P<0.05)$; $(2)$ Protocol I patients improved significantly in 9 categories $(P<0.05)$ but failed to ameliorate in 2 categories, "Emotion" and "Alertness.",

Patients treated with GBP + ROP showed a significant improvement in total SIP scores (Quality of Life) after the period of treatment (day 0: GBP, $687.8 \pm 124.4$; GBP + ROP, $676.7 \pm 169.8$; day 28: GBP, $543.2 \pm 60.7$; $\mathrm{GBP}+\mathrm{ROP}, 476.3 \pm 60.6 ; \quad P=0.038$, Mann-Whitney, $U=36.00, z=-2.078$; Fig. 6).

\section{DISCUSSION}

In the present study, we evaluated possible therapeutic alternatives for $\mathrm{TN}$ patients who cannot be treated with the main $\mathrm{AC}$ drug used for pain control (CBZ). The clinical efficacy of associating GBP and ROP for $\mathrm{TN}$ treatment was determined by measuring pain intensity, number of paroxysmal pain crises, NNT, and Quality of Life provided to the patients. GBP monotherapy (Protocol I), ROP administration to trigger points (Protocol II), and the proposed GBP + ROP association (Protocol III) have all resulted in a significant reduction of the initial pain intensity and number of crises. However, patients treated with the association of GBP + ROP presented (1) a faster clinical improvement, (2) a significantly higher reduction of pain (VAS and 


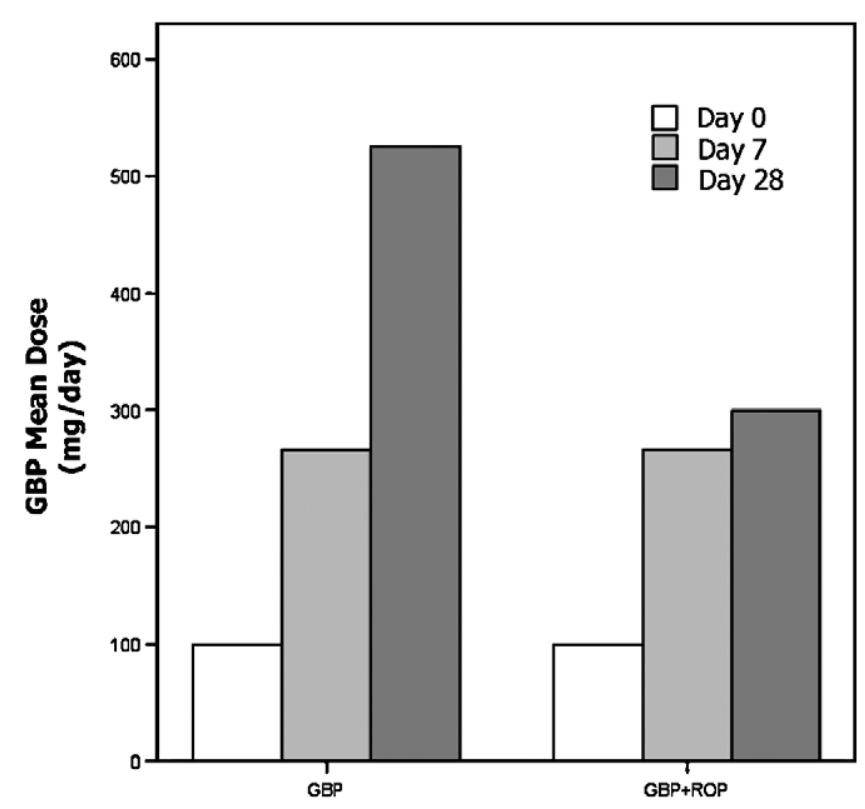

FIGURE 5. Longitudinal evolution of the daily dose of GBP administered during treatment Protocols I and III. Prolonged therapy with GBP+ROP needs significantly smaller doses of GBP than GBP-only protocol at the end of the 28-day treatment period.

NNT scores), (3) an inferior daily dose of GBP, and (4) a better Quality of Life than patients treated only with GBP. On the other hand, it was clear that ROP alone applied to TN trigger points (Protocol II) was sufficient for a reliable satisfactory pain control in some but not all patients.

\section{Study Design and Methodologic Considerations}

To perform this study, several aspects needed to be addressed owing to the specific nature of TN pain. First, the rationale was to increase the efficacy of $\mathrm{GBP}^{13}$ in $\mathrm{TN}$

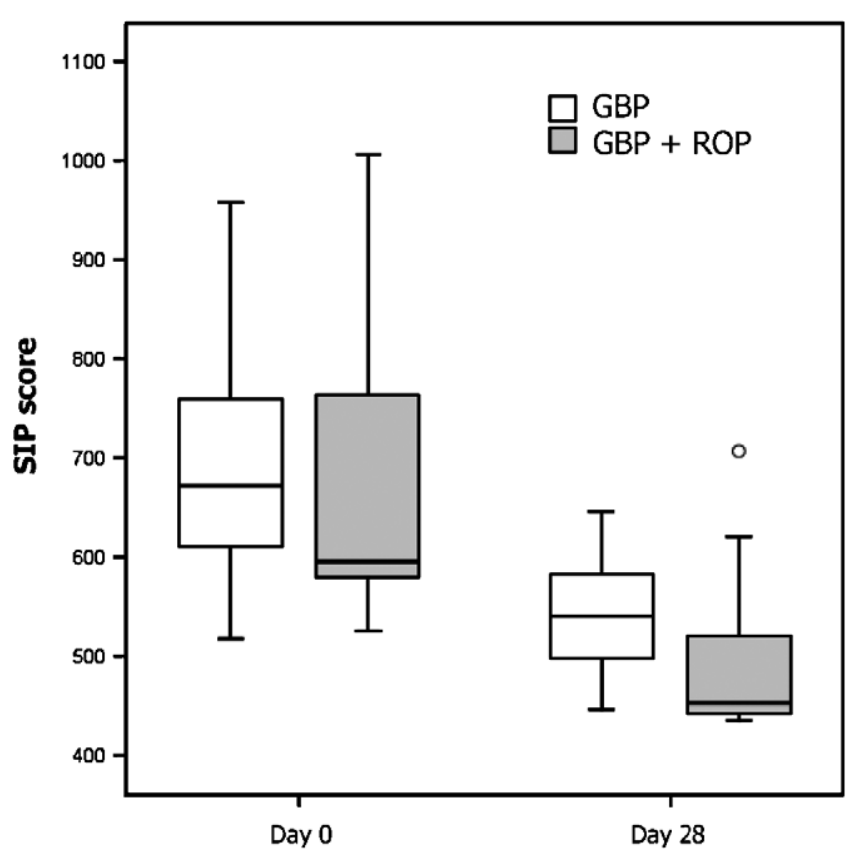

FIGURE 6. Effect of Protocols I and III (GBP and GBP+ROP) on the total SIP score of Quality of Life. Note that no differences were observed at the beginning of the treatment (day 0) between both patient groups. However, at the end of the treatment (day 28), Protocol III induced a significant decrease in the total SIP score, which indicates an improvement in the Quality of Life of TN patients.

to provide an improved alternative to patients where the primary treatment with CBZ failed or cannot be applied; thus, it was not an objective of the study to evaluate an alternative to CBZ as a first choice drug treatment for TN pain. The possibility of associating GBP with a local anesthetic in analgesic concentration occurred when pilot studies of our group, using the administration of ROP as a rescue analgesic in TN paroxysmal pain crises, showed

TABLE 2. Scores of the Different Categories of the Quality of Life SIP Questionnaire Evaluated at the Beginning and End of TN Therapeutical Protocols I and III

\begin{tabular}{|c|c|c|c|c|c|c|c|c|}
\hline \multirow[b]{3}{*}{ SIP Categories } & \multicolumn{4}{|c|}{ GBP (Protocol I) } & \multicolumn{4}{|c|}{ GBP + ROP (Protocol III) } \\
\hline & \multicolumn{2}{|c|}{ Day 0} & \multicolumn{2}{|c|}{ Day 30} & \multicolumn{2}{|c|}{ Day 0} & \multicolumn{2}{|c|}{ Day 30} \\
\hline & Mean & SD & Mean & SD & Mean & SD & Mean & SD \\
\hline Wellbeing & 81.11 & 28.49 & 34.28 & 3.76 & 52.55 & 26.82 & 33.20 & 2.85 \\
\hline Mobility & 63.81 & 15.16 & 46.27 & 11.81 & 75.66 & 10.34 & 43.71 & 7.83 \\
\hline Domestic Work & 71.95 & 21.78 & 55.56 & 17.58 & 68.61 & 22.15 & 53.61 & 8.58 \\
\hline Eating & 40.85 & 17.75 & 25.35 & 4.39 & 53.38 & 24.86 & 29.95 & 12.50 \\
\hline Recreation and Pastime & 65.29 & 20.01 & 54.12 & 17.84 & 63.58 & 23.95 & 45.26 & 17.69 \\
\hline Social Interaction & 80.09 & 25.47 & 74.63 & 24.45 & 86.02 & 19.14 & 66.11 & 23.59 \\
\hline Alertness & 60.73 & 10.58 & 58.48 & 9.48 & 56.23 & 23.68 & 45.87 & 12.11 \\
\hline Rest & 74.40 & 11.50 & 70.87 & 8.14 & 68.62 & 17.34 & 63.07 & 12.05 \\
\hline Total SIP Score & 687.78 & 124.43 & 543.22 & 60.71 & 676.73 & 169.75 & 495.50 & 88.11 \\
\hline
\end{tabular}

Italics indicate that there was a significant improvement $(P<0.05)$ in that category between days 0 and 30 of treatment.

Note that GBP + ROP-treated patients showed improvement in all categories analyzed, whereas GBP patients did not improve in 2 categories of the SIP. 
a prolonged pain free state that largely overcame the normal period of ROP local analgesia (72 h). Although pain relief outlasting by days, weeks, or months, the short duration of the pharmacologic action of local anesthetics like ROP has been documented, a clear explanation for this effect is not currently available. ${ }^{21,22,36}$ It is possible that the prolonged effect is based not only on the pharmacologic effect of the drug but also on the physical action of local administration of the analgesic solution by clearing adhesions or inflammatory exudates from the vicinity of the nerve. ${ }^{22}$ These mechanisms may explain the improvement observed in a set of TN patients entered into Protocol II (ROP only) treatment during this study. In fact, trigeminal nerve block analgesia is a procedure considered already as a TN treatment when pharmacologic approaches have failed. ${ }^{22}$

Although other possibilities have been raised, we decided that the third group of our study (in addition to GBP and GBP + ROP) should be ROP treatment alone. A second alternative could have been the administration of saline injections upon TN trigger points in a group of GBP patients; although protected by using GBP and acting as a placebo for ROP, this group would not rule out the physical effect of administering a volume of liquid to each trigger point. A third alternative, the possibility of having a study branch with just saline administration to the trigger points would be unethical and was not considered, because no pain control would be achieved and, on the contrary, it could induce paroxysmal pain crises. Thus, by using a third group of patients treated with ROP monotherapy, we evaluated the degree of pain control that can be achieved just by the local analgesia plus the physical effect of liquid administration to trigger points.

The frequency and number of ROP injections applied to TN patients followed the guidelines for the practice of interventional techniques described by Manchikanti et al. ${ }^{22}$ It is advisable that in the stabilization phase, a patient should receive an injection at intervals not smaller than 1 week, which was the period chose to mediate between each ROP administration. The followup evaluation of patients treated with Protocols I and III, it was performed by phone interview; consequently, while the determination of the number of pain crises could be assessed 6 and 12 months after the beginning of the treatment, the pain intensity measured in a VAS scale was obviously not possible to perform.

\section{Clinical Significance of the GBP+ROP Association}

A 2-point decrease in the mean VAS scale (0 to 10 scale) has been considered the minimum clinical relevant difference in pain intensity when comparing the effect of 2 treatments. ${ }^{26-28}$ Taking into account that GBP, ROP, and $\mathrm{GBP}+\mathrm{ROP}$ treatments decreased pain intensity between 3.4 and 6.0 VAS points, all protocols were clinically effective in reducing pain after a 1-month therapy. When comparing with GBP protocol, it is relevant to note that $\mathrm{GBP}+\mathrm{ROP}$ was not only more efficient in reducing pain intensity at the end of the treatment, but was the only protocol being clinically effective in reducing pain after 7 days of treatment. This suggests a potentiation or synergism between the $\mathrm{AC}$ and local analgesic effects when associated in the same protocol. Curiously, ROP administration alone resulted in a pain decrease at the end of 28day treatment about as significant as the GBP + ROP association, but the follow-up evaluation was not so efficient. Although a careful systematic administration of ROP to TN trigger points has been performed in patients following Protocols II and III, further studies are needed to determine the causes for the great variability and unpredictability of pain control obtained in patients submitted only to local analgesic block.

\section{GBP Dose and Quality of Life}

TN treatment with titrated GBP was adapted from other studies ${ }^{16}$ and is used in several pain units in Portugal. It started with a $100-\mathrm{mg}$ daily administration that is gradually increased by 100 to $300 \mathrm{mg}$ each 3 to 5 days until patients refer a satisfactory pain relief $(\mathrm{VAS}<6)$ or intolerable side effects ${ }^{16}$ (but see, initial dose 300 to $900 \mathrm{mg} / \mathrm{d}^{9,10,37}$ ). Clinically effective GBP doses given monotherapeutically are usually placed between 900 and $1200 \mathrm{mg} / \mathrm{d}$ but may reach concentrations as high as $3600 \mathrm{mg} / \mathrm{d} .{ }^{16,37,38}$ To evaluate the best GBP dose to be administered to each patient, the GBP dose in our study started at $100 \mathrm{mg} / \mathrm{d}$ in all protocols. At the end of the treatment (day 28), the mean GBP daily administration in patients treated with GBP + ROP was $300 \mathrm{mg} / \mathrm{d}$, just a little higher that the dose at the seventh day. On the contrary, patients treated with GBP monotherapy needed significantly higher doses of GBP $(525 \mathrm{mg} / \mathrm{d})$ with the mean dose on day 28 being the double of that recorded at day 7. These data show that the clinical result of NT treatment with GBP + ROP is superior to GBP monotherapy, because the low dose of GBP needed along Protocol III did not result in a single patient showing the usual side effects associated with GBP, sedation, ataxias, and dizziness. ${ }^{39}$ The possibility of GBP subtherapeutic treatment was excluded, as shown by the significant pain decrease and improvement of Quality of Life.

The evaluation of Quality of Life in TN patients revealed a clear beneficial effect in 9 of the 11 categories analyzed with $\operatorname{SIP}^{32,33}$ in patients treated with GBP + ROP, whereas GBP-only treated patients showed improvement in 9 categories. Thus, the general functional well-being of TN patients improved significantly in more SIP categories following the GBP + ROP protocol. Accordingly, the longitudinal analysis of the SIP total score showed a significant improvement in the functional status of GBP + ROP patients.

\section{Potential Mechanisms Mediating GBP+ROP Therapeutic Association}

To the best of our knowledge, no studies have evaluated the clinical effect of associating an AC with another drug therapy for treating TN. ${ }^{1,2,37}$ This fact is 
intriguing because pain reduction with ACs seems to decrease pain only about $30 \%$ owing to incomplete efficiency, adverse side effects, or both. ${ }^{40-42}$ Even for treating neuropathic pain in general, only a recent study associating GBP and morphine applied to patients with diabetic neuropathy and postherpetic neuralgia is worth mentioning owing to the significant reduction of daily pain intensity measured by the VAS scale and McGill Pain Questionnaire. ${ }^{40}$

Complementary mechanisms associated with the local analgesic action of ROP and GBP may be at the basis for the strong pain reduction resulting from the association of both therapies in Protocol III. Low-dose ROP has an analgesic action similar to CBZ, because both drugs act on voltage-gated sodium channels, ${ }^{11,43,44}$ reducing the membrane potential oscillations and membrane excitability associated to neuropathic pain ${ }^{45}$ but not blocking nerve conduction. ${ }^{15,44}$ GBP also suppresses ectopic afferent discharge activity generated by injured peripheral fibers, ${ }^{10,46}$ without blocking nerve conduction. ${ }^{15,40}$ The analgesic action of GBP is not based on blocking sodium channels along nerve fibers ${ }^{47,48}$ but on voltage-gated calcium channels containing the $\alpha 2 \delta$ subunit. ${ }^{49,50}$ Calcium channels are essential for modulation of cell-membrane excitability and thus are implicated in neuropathic pain, ${ }^{51}$ with the expression of the $\alpha 2 \delta$ subunit being increased in some neuropathic models. ${ }^{52}$ These channels are also essential for the release of central neurotransmitters from axonal terminal boutons to the synaptic gap ${ }^{51}$ and pregabalin (a close structural relative of GBP) binding to the $\alpha 2 \delta$ subunit reduces their presynaptic liberation. ${ }^{53}$ The importance of this effect in GBP action is not known as ACs that act synaptically (eg, barbiturates) are largely ineffective as analgesics. ${ }^{15}$ According to the "ignition hypothesis" of TN, ${ }^{15,54,55}$ pain paroxysms begin with discharges in a small set of trigeminal primary afferents resulting from spontaneous activation or after cutaneous trigger point stimulation. Crossed-afterdischarge then excites nonstimulated neighbor fibers through a "windup" mechanism that selfsustains fiber activity beyond the original focal fiber discharge. It should also be pointed that a central effect of ROP may exist owing to some degree of systemic circulation. ${ }^{15}$ Thus, it is possible that the therapeutic value of the present GBP + ROP association may result from the synergistic/additive control of (1) fiber depolarization at trigger points (by ROP), (2) crossedafterdischarge of passive neighboring neurons at the trigeminal ganglion (by GBP and ROP), and (3) central neurotransmitter release from primary afferents (GBP).

\section{Limitations of the Study}

There are 4 main limitations to the present study. First, the generalization of the findings to all patients who do not tolerate drug therapy after CBZ should be made with caution because no comparisons were made with other ACs that can be alternative to the main treatment. The exclusion criteria were extensive and $14 \%$ of $\mathrm{TN}$ patients arriving to the Pain Unit were withdrawn from the study, which indicates that the data need to be confirmed in a less homogenous population. Second, although all effort has been made to avoid patients meeting with each another within and between protocols and all patients from the 3 protocols have been evaluated by the hospital staff, it was not possible to blind patients to therapeutic group (ROP injection vs. no injection). Thus, the study was blinded only to the research staff. Third, it was only possible to perform the follow-up by phone interview, which precluded the possibility of evaluating the Quality of Live in patients since the SIP has 136 questions. Consequently, patients' VAS pain was used as a surrogate measure. Patients were also trained to count their number of daily pain periods and this measure was also obtained at the follow-up. Finally, although the therapeutic effect on the number of crises was still significantly different after a year of treatment with GBP + ROP and ROP, the follow-up period may not have been sufficient to determine the long-term effect of the proposed treatment.

\section{CONCLUSIONS}

GBP is already the first choice drug therapy for all types of neuropathic chronic pain in several international pain control centers, owing to the facility of monitoring, relatively low incidence of adverse side effects, lack of interaction with other drugs acting on the nervous system, and evident perception of its efficacy. ${ }^{10,11,56,57}$ However, concerning TN, CBZ has been the most widely used drug therapy, with significant results on pain relief obtained in large scale placebo studies. ${ }^{5,8}$ On the other hand, whenever CBZ fails to control TN pain, GBP is an alternative for reducing its intensity. ${ }^{13,14}$ The present study indicates that the association of oral GBP and peripheral analgesic block with low-dose ROP results in a clinical pain control of TN with a rapidity, a decrease in pain intensity and a long-term action that is superior to GBP monotherapy. This is reinforced by complete lack of adverse side effects and the global improvement of the functional Life Quality of TN patients submitted to GBP + ROP therapeutic association. However, largescale GBP studies are needed to place more accurately GBP in the spectrum of drugs that can be used in TN pain control.

\section{ACKNOWLEDGMENTS}

The authors thank the Clinical Director of the Hospital Center of Alto Ave (Fafe Unit) and the Chronic Pain Unit team of the same Hospital for the collaboration in this study.

\section{REFERENCES}

1. Zakrzewska JM, Lopez BC. Trigeminal and glossopharyngeal neuralgia. In: McMahon SB, Koltzenburg M, eds. Wall and Melzack's Textbook of Pain. 5th ed. Churchill Livingstone: Elsevier; 2006:1001-1010.

2. Loeser JD. Cranial neuralgias. In: Loeser JD, Butler SH, Chapman $\mathrm{CR}$, et al, eds. Bonica's Management of Pain. 3rd ed. Philadelphia: Lippincott Williams \& Williams; 2001:855-866. 
3. Merrison AFA, Fuller G. Treatment options in trigeminal neuralgia. BMJ. 2003;327:1360-1361.

4. Chong MS, Bajwa ZH. Diagnosis and treatment of neuropathic pain. J Pain Sympt Manag. 2003;25(5S):S4-S11.

5. Wiffen PJ, McQuay HJ, Moore RA. Carbamazepine for acute and chronic pain. Cochrane Database Syst Rev. 2005;20:CD005451.

6. Jensen TS. Anticonvulsants in neuropathic pain: rationale and clinical evidence. Eur J Pain. 2002;6:61-68.

7. Taylor JC, Brauer S, Espir MLE. Long-term treatment of trigeminal neuralgia with carbamazepine. Postgrad Med J. 1981;57:16-18.

8. Zakrzewska JM. Trigeminal, eye, and ear pain. In: Melzack R, Wall PD, eds. Handbook of Pain Management-A Clinical Companion to Wall and Melzack's Textbook of Pain. London: Churchill Livingstone; 2003:199-215.

9. Khan AO. Gabapentin relieves trigeminal neuralgia in multiple sclerosis patients. Neurology. 1998; 51:611-614.

10. Tremont-Lukats IW, Megeff C, Backonja MM. Anticonvulsivants for neuropathic pain syndromes: mechanisms of action and place in therapy. Drugs. 2000;60:1029-1052.

11. Rowbotham MC, Petersen KL. Anticonvulsants and local anesthetic drugs. In: Loeser JD, Butler SH, Chapman CR, eds. Bonica's Management of Pain. 3rd ed. Philadelphia: Lippincott Williams \& Williams; 2001:329-341.

12. Wiffen PJ, Collins S, McQuay H, et al. Gabapentin for acute and chronic pain. Cochrane Database Syst Rev. 2005;20:CD005452.

13. Cheshire WP Jr. Defining the role for gabapentin in the treatment of trigeminal neuralgia: a retrospective study. J Pain. 2002;3:137-142.

14. Solaro C, Messmer Uccelli M, Uccelli A, et al. Low-dose gabapentin combined with either iamotrigine or carbamazepine can be useful therapies for trigeminal neuralgia in multiple sclerosis. Eur Neurol. 2000;44:45-48.

15. Devor M. Responses of nerves to injury in relation to neuropathic pain. In: McMahon SB, Koltzenburg M, eds. Wall and Melzack's Textbook of Pain. 5th ed. Churchill Livingstone: Elsevier; 2006: 905-927.

16. Ahmad M, Goucke CR. Management strategies for the treatment of neuropathic pain in the elderly. Drugs Aging. 2002;19:929-945.

17. Lemos L, Macedo G, Flores S, et al. Gabapentine plus ropivacain: a significant improvement in the treatment of trigeminal neuralgia. 4th FENS Meeting. 2004;121.10.

18. Moher D, Schulz KF, Altman DG, for the CONSORT Group. The CONSORT statement: revised recommendations for improving the quality of reports of parallel-group randomised trials. Lancet. 2001;357:1191-1194.

19. Schulz KF, Grimes DA. Allocation concealment in randomised trials: defending against deciphering. Lancet. 2002;359:614-618.

20. Doig GS, Simpson F. Randomization and allocation concealment: a practical guide for researchers. J Crit Care. 2005;20:187-193.

21. Breivik H. Local anesthetic blocks and epidurals. In: McMahon SB, Koltzenburg M, eds. Wall and Melzack's Textbook of Pain. 5th ed. Churchill Livingstone: Elsevier; 2006:903-925.

22. Manchikanti L, Singh V, Trescot AM, et al. Guidelines for the practice of interventional techniques. In: Boswell MV, Cole BE, eds. Weiner's Pain Management: A Practical Guide for Clinicians. 7th ed. CRS Press; 2006:847-878.

23. McCoffery M, Pasero C. Assessment-underlying complexities, misconceptions and practical tools. In: Bowlus B, ed. Pain Clinical Manual. St Louis: Mosby Inc; 1999:35-99.

24. Chapman CR, Syrjala KL. Measurement of pain. In: Loeser JD, Butler SH, Chapman CR, et al, eds. Bonica's Management of Pain. 3rd ed. Philadelphia: Lippincott Williams \& Williams; 2001: 310-328.

25. Collins SL, Moore RA, McQuay HJ. The visual analogue pain intensity scale: what is moderate pain in millimeters? Pain. 1997;72:95-97.

26. Farrar JT, Portenoy RK, Berlin JA, et al. Defining the clinically important difference in pain outcome measures. Pain. 2000;88: 287-294.

27. Finnerup NB, Sindrup SH, Bach FW, et al. Lamotrigine in spinal cord injury pain: a randomized controlled trial. Pain. 2002;96: 375-383.
28. Salaffi F, Stancati A, Silvestri CA, et al. Minimal clinically important changes in chronic musculoskeletal pain intensity measured on a numerical rating scale. Eur J Pain. 2004;8:283-291.

29. Cook RJ, Sackett DL. The number needed to treat: a clinically useful measure of treatment effect. BMJ. 1995;310:452-454.

30. McQuay HJ, Moore A. Methods of therapeutic trials. In: McMahon SB, Koltzenburg M, eds. Wall and Melzack's Textbook of Pain. 5th ed. Churchill Livingstone: Elsevier; 2006:415-425.

31. Altman DG. Confidence intervals for the number needed to treat. BMJ. 1998;317:1309-1312.

32. Bergner M, Bobbitt RA, Carter WB, et al. The Sickness Impact Profile: development and final revision of a health status measure. Med Care. 1981;19:787-805.

33. Turner JA, Romano JM. Psychological and psychosocial evaluation. In: Loeser JD, Butler SH, Chapman CR, et al, eds. Bonica's Management of Pain. 3rd ed. Philadelphia: Lippincott Williams \& Williams; 2001:329-341.

34. Jamison RN. The role of psychological testing and diagnosis in patients with pain. In: Dworkin RH, Breitbart WS, eds. Psychological Aspects of Pain: A Handbook for Health Care Providers. Progress in Pain Research and Management. Vol 27. Seattle: IASP Press; 2004;117-137.

35. Montgomery DC. Design and Analysis of Experiments. 3rd ed. John Wiley \& Sons; 1991

36. Arnér A, Lindblom U, Meyerson BA, et al. Prolongad relief of neuralgia alter regional anesthetic blocas. A call for further experimental and systematic clinical studies. Pain. 1990;43:287-297.

37. Nurmikko TJ. Trigeminal neuralgia and other facial neuralgias. In: Cervero F, Jensen TS, eds. Handbook of Clinical Neurology-Pain, Vol 81 (3rd series). London: Elsevier; 2006:574-596.

38. Backonja M, Glanzman RL. Gabapentin dosing for neuropathic pain: evidence from randomized, placebo-controlled clinical trials. Clin Ther. 2003:25:81-104.

39. Marson AG, Kadir ZA, Hutton JL, et al. The new antiepileptic drugs: a systematic review of their efficacy and tolerability. Epilepsia. 1997;38:859-880.

40. Gilron I, Bailey JM, Dongsheng T, et al. Morphine, gabapentin, or their combination for neuropathic pain. $N$ Eng J Med. 2005;352: 1324-1334.

41. Rowbotham M, Harden N, Stacey B, et al. Gabapentin for the treatment of postherpetic neuralgia: a randomized controlled trial JAMA. 1998;280:1837-1842.

42. Backonja M, Beydoun A, Edwards KR, et al. Gabapentin for the symptomatic treatment of painful neuropathy in patients with diabetes mellitus: a randomized controlled trial. JAMA. 1998;280: 1831-1836.

43. Burchiel KJ. Carbamazepine inhibits spontaneous activity in experimental neuromas. Exper Neurol. 1988;102:249-253.

44. Devor M, Wall PD, Catalan N. Systemic lidocaine silences ectopic neuroma and DRG discharge without blocking nerve conduction. Pain. 1992;48:261-268.

45. Amir R, Michaelis M, Devor M. Membrane potential oscillations in dorsal root ganglion neurons: role in normal electrogenesis and neuropathic pain. J Neurosci. 1999;19:8589-8596.

46. Pan H-L, Eisenach JC, Chen S-R. Gabapentin suppresses ectopic discharge and reverses allodynia in neuropathic rats. $J$ Pharmacol Expl Ther. 1999;288:1026-1030.

47. Sang CN, Hayes KS. Anticonvulsant medications in neuropathic pain. In: McMahon SB, Koltzenburg M, eds. Wall and Melzack's Textbook of Pain. 5th ed. Churchill Livingstone: Elsevier; 2006: 499-506.

48. Roza C, Laird JMA, Souslova V, et al. The tetrodoxin-resistant $\mathrm{Na}+$ channel Nav1.8 is essential for the expression of spontaneous activity in damaged sensory axons of mice. J Physiol. 2003;550 921-926.

49. Sills $\mathrm{G}$. The mechanism of action of gabapentin and pregabalin. Curr Opin Pharmacol. 2006;6:108-113.

50. Gee NS, Brown JP, Dissanayake VU. The novel anticonvulsant drug gabapentin (Neurontin) binds to the alpha-2 delta subunit of calcium channel. J Bio Chem. 1996;271: $5786-5776$. 
51. Gribkoff VK. The role of voltage-gated calcium channels in pain and nociception. Sem Cell Devel Biol. 2006;17:555-564.

52. Luo ZD, Chaplan SR, Higuera ES, et al. Upregulation of dorsal root ganglion $\alpha 2 \delta$ calcium channel subunit and its correlation with allodynia in spinal nerve-injured rats. J Neurosci. 2001;21: $1868-1875$.

53. Joshi I, Taylor CP. Pregabalin action at a model synapse: binding to presynaptic calcium channel alpha2-delta subunit reduces neurotransmission in mice. Eur J Pharmacol. 2006;553:82-88.
54. Rappaport ZH, Devor M. Trigeminal neuralgia: the role of selfsustaining discharge in the trigeminal ganglion. Pain. 1994;56:127-138.

55. Devor M, Amir R, Rappaport ZH. Pathophysiology of trigeminal neuralgia: the ignition hypothesis. Clin J Pain. 2002;18:4-13.

56. Backonja MM. Anticonvulsivants (antineuropathics) for neuropathic pain syndromes. Clin J Pain. 2000;16(suppl 2):S67-S72.

57. Rosen TD. Antiepileptic drugs in the management of cluster headache and trigeminal neuralgia. Headache. 2001;41(suppl 1): S25-S32. 